\title{
OPEN High species richness of tachinid parasitoids (Diptera: Calyptratae) sampled with a Malaise trap in Baihua Mountain Reserve, Beijing, China
}

Wenya Pei $\circledast^{1}$, Liping Yan ${ }^{1}{ }^{1}$, Thomas Pape $\mathbb{1}^{2}$, Qike Wang ${ }^{3}$, Chuntian Zhang ${ }^{4}$, Nan Yang $\circledast^{5}$, Fuxin Du ${ }^{5}$ \& Dong Zhang ${ }^{1 凶}$

Tachinidae are one of the most speciose families of Diptera and the largest group of nonhymenopteran parasitoids. Little is known about their diversity, distribution patterns, and seasonal variation in most ecosystems. This study reports on tachinid flies collected by a Malaise trap over 73 weeks in Baihua Mountain Reserve, northern China, and investigates the patterns of local species richness and its temporal distribution. The most species-rich season was summer, but the majority of specimens were recovered in spring. A total of 755 tachinid specimens were collected, consisting of 144 species in 85 genera, comprising $26.5 \%$ of the species and $49.7 \%$ of the genera recorded from northern China. A total species richness of 243 was estimated, indicating that only a portion of the community of tachinid flies was collected at this location and suggesting that the diversity of tachinids might be underestimated across Beijing and northern China. This work is a first step in assessing patterns of tachinid diversity in China using quantitative sampling and establishes a baseline for comprehending the temporal and spatial diversity of these ecologically significant parasitoids.

More than 30 years ago, in a seminal paper, Edward O. Wilson ${ }^{1}$, a pioneer in biodiversity research, stated that insects were the little things that rule the world. Insects dominate terrestrial ecosystems in terms of numbers and species richness $^{2-5}$. They have sparked wide interest because of their great diversity and importance in ecosystem function and stability, and the estimation of global insect species richness has been investigated for over 270 years ${ }^{2,3,6-12}$. Understanding the species richness and taxonomic composition of an ecosystem or in a region is key for its proper safeguarding and sustainable utilization ${ }^{11-13}$. Such studies can provide baseline data for local ecological processes and can be used to monitor the response of animal and plant communities to climate change, natural disturbances or intensification of anthropogenic activities ${ }^{11,14}$. Many researchers have demonstrated that species richness of insect communities changes over time, both seasonally and annually ${ }^{15,16}$. However, due to the logistic and financial challenges of long-term continuous sampling, few entomological surveys have been able to reveal the temporal complexity of insect communities ${ }^{13,17-19}$.

The methods of sampling are critically important for the accurate assessment of species richness of insect communities. Several methods have been widely applied in previous studies, including sweep nets, sticky traps, light traps, baited traps, pit-fall traps, Malaise traps, etc $^{20}$. Among them, Malaise traps provide a relatively more systematic approach to surveying, and have been used successfully to monitor changes in the species composition of terrestrial communities and biodiversity assessments across the world ${ }^{9,10}$. Malaise traps are time- and cost-effective as they can continuously monitor an area with minimal human resources, as sampling efforts can be standardized by deploying them at fixed intervals. Thus, they are especially advantageous in the study of Diptera and Hymenoptera ${ }^{21-25}$. However, several studies on the effectiveness of Malaise traps have shown that less intensive trapping at a single site can provide sufficient information on the most abundant species ${ }^{10,23}$.

${ }^{1}$ School of Ecology and Nature Conservation, Beijing Forestry University, Beijing, China. ${ }^{2}$ Natural History Museum of Denmark, University of Copenhagen, Copenhagen, Denmark. ${ }^{3}$ School of BioSciences, University of Melbourne, Victoria, Australia. ${ }^{4}$ College of Life Science, Shenyang Normal University, Shenyang, China. ${ }^{5}$ Serving Officer in Administration Department of Baihua Mountain Reserve, Beijing, China. ${ }^{\circledR}$ email: zhangdong_bjfu@bjfu.edu.cn 


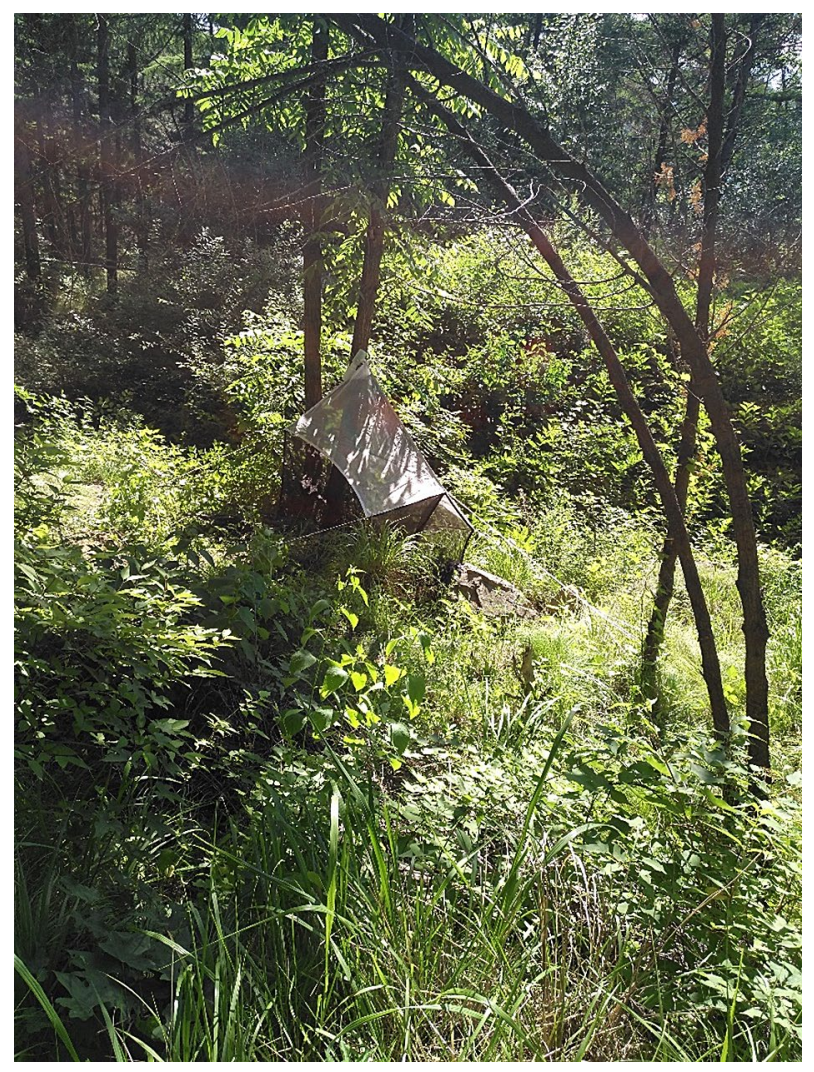

Figure 1. The Malaise trap deployed in the collecting site.

Tachinidae is an amazingly diverse Diptera family that contains exclusively parasitoid species and is distributed worldwide (ca. 8,500 described spp.) ${ }^{26,27}$. Tachinids are the largest group of non-hymenopteran parasitoids, and as parasitoids of herbivorous insects ${ }^{28}$, and thus are of great ecological importance in both natural and managed ecosystems. They primarily seek hosts among immature stages of herbivorous Lepidoptera, Hemiptera and Coleoptera $^{28-30}$, and their diversity and population dynamics are suggested to reflect that of their hosts ${ }^{30}$. Understanding the temporal and spatial variation of tachinid diversity could indicate the health of local communities and may provide a basis for conservation work ${ }^{31}$. In addition, monitoring the temporal abundance of tachinids provides basic biological information on their voltinism, timing of development, and association with potential hosts, which is essential in assessing their effectiveness as potential means of biological control for pests ${ }^{32}$.

So far, only a few studies have quantified the species richness of local tachinids over different seasons in the Palaearctic Region ${ }^{31-34}$. In China, among the previous biodiversity surveys focused on tachinid species ${ }^{35-41}$, only a few documented or assessed the species richness and composition of tachinid communities in a certain geographic location. In this study, we collected tachinids using Malaise traps with continuous sampling over three seasons in the Baihua Mountain Reserve in Beijing, Northeastern China. Baihua Mountain Reserve forms an important ecological barrier for Beijing, and is known for its high biodiversity, environmental heterogeneity, and varied climate. This study aims to: (i) produce a species list as a baseline database of the Tachinidae in Baihua Mountain Reserve; (ii) estimate the total species richness of the tachinid community in the study area; (iii) examine how tachinid abundance and species richness vary over seasons; and (iv) assess voltinism and phenological patterns for several species of the tachinid community.

\section{Materials and methods}

Study area. The sampling was conducted in Baihua Mountain Reserve, Northeastern China. The study site is located at the forest-farmland edge where grass and shrubland successions occurred after the artificial coniferous forests were cut down (N39 50'11.04", E115'34'41.52", 1224 m; Fig. 1). Common plant species in this study site are Rosaceae (Spiraea spp., Rubus spp., Agrimonia spp.), Saxifragaceae (Deutzia spp.), Dioscoreaceae (Dioscorea spp.), and Lamiaceae (Phlomis spp.). The large areas of woodland in the immediate vicinity of the site are dominated by trees of the families Pinaceae (Larix spp., Pinus spp.), Juglandaceae (Juglans spp.) and Salicaceae (Populus spp., Salix spp.).

Specimen collecting. A single $1.8 \mathrm{~m}$ long and $1.7 \mathrm{~m}$ high Townes-type Malaise trap (Fig. 1) was deployed in the center of an open area approximately $20 \mathrm{~m} \times 30 \mathrm{~m}$ for 73 weeks (4th June to 27th October in 2017 and from 6th July in 2018 to 6th July in 2019). Samples were collected every week and deposited in the Museum of Beijing 


\begin{tabular}{|l|l|l|l|l|l|l|l|l|l|l|}
\hline \multirow{2}{*}{ Estimator } & 2017 & $\mathbf{2 0 1 8}$ & $\mathbf{2 0 1 9}$ & \multicolumn{2}{l|}{$\mathbf{2 0 1 8 - 2 0 1 9}$} & $2017-2019$ \\
\cline { 2 - 11 } & By specimens & By samples & By specimens & By samples & By specimens & By samples & By specimens & By samples & By specimens & By samples \\
\hline No. of observations & 248 & 10 & 188 & 8 & 319 & 8 & 507 & 16 & 755 \\
\hline Species observed & 73 & 73 & 55 & 55 & 54 & 54 & 94 & 94 & 144 \\
\hline Chao-1 & 161 & 161 & 111 & 111 & 78 & 78 & 152 & 152 & 243 \\
\hline $\begin{array}{l}\text { Chao-1 (lower- } \\
\text { upper) }\end{array}$ & $111-278$ & $111-278$ & $76-202$ & $76-202$ & $63-119$ & $63-119$ & $120-220$ & $120-220$ & $196-333$ & $196-333$ \\
\hline
\end{tabular}

Table 1. Estimates of total species richness of the tachinid community by specimens and samples for 2017, 2018, 2019, 2018-2019 and 2017-2019, based on 1,000 randomizations.

Forestry University, Beijing, China. The field work permission was approved by the Baihua Mountain Reserve and was performed in accordance with relevant guidelines of the reserve.

Identification. The systematic order and nomenclature follow those of Herting and Dely-Draskovits ${ }^{42}$ and O'Hara and Henderson ${ }^{43}$, and the genus level classification was based primarily on Tschorsnig and Richter ${ }^{44}$ and Cerretti et al ${ }^{45}$ All the tachinid specimens were identified to the species level with integration of the recent literature $27,43,44,46-53$.

Analysis. We used EstimateS 9.1.0 software package for Windows ${ }^{54}$ to estimate the total species richness based on the classic Chao 1 Richness Estimator (Chao-1), Incidence Coverage-based Estimator (ICE) and Abundance Coverage-based Estimator (ACE). The rarefaction curve and its $95 \%$ confidence intervals (95\% CL) were calculated and plotted using 1,000 permutations. Each sample corresponded to the pooled catches from two weeks, thereby representing specimens collected the first and second half of each month respectively. To explore the patterns of species composition over time, we used a Non-metric Multidimensional Scaling (NMDS) ordination plot with the 'vegan ${ }^{55}$ package implemented in R, following construction of Bray-Curtis dissimilarity metrics. Differences in tachinid communities were further quantified by a Multi Response Permutation Procedure (MRPP) analysis ${ }^{56}$ using the 'vegan' package in R. MRPP was performed with 999 permutations on Bray-Curtis distance. The seasonal preference of different tachinid species was estimated by the indicator species analysis ${ }^{57}$ using PC-ORD (version 5.0) for Windows ${ }^{58}$. Only tachinid species with an observed indicator value (IV) $>50$ and statistical significance $\mathrm{P}<0.05$ (in a Monte Carlo test (MCT) with 499 permutations) were considered to have a significant preference for a certain season.

\section{Results}

Species composition. During the sampling period, no tachinid specimens were collected between 26th October 2018 and 28th February 2019. A total of 755 tachinid specimens were collected and sorted into 144 species (100 named species, 43 morphospecies, and one undescribed species) belonging to four subfamilies, 21 tribes and 85 genera (Supplementary Information File 1). We collected 248 specimens (73 spp.) in 2017 and 507 specimens (94 spp.) from July 2018 to July 2019 (Table 1). Exoristinae was the most abundant subfamily in terms of species richness (78 spp.) and abundance (322 specimens), followed by subfamily Tachininae (41 spp., 284 specimens) (Fig. 2). Subfamilies Dexiinae and Phasiinae comprised less than $20 \%$ of the material (24 spp., 148 specimens) (Fig. 2). At the tribal level, Blondeliini (Exoristinae) was the most speciose (31 spp.), followed by Goniini (Exoristinae) (24 spp.), while the most abundant were Siphonini (157 specimens) and Goniini (102 specimens). At the genus level, Siphona was both most speciose and most abundant (7 spp., 97 specimens). Phorocera normalis (Chao) was the most dominant species (89 specimens) during the sampling period (Supplementary Information File 1). Of the 144 species identified in this study, $45.8 \%$ were represented by only one specimen, $31.9 \%$ represented by two specimens, and only $11.8 \%$ were well represented by more than 10 specimens (Fig. 3).

Species richness. The species accumulation curve based on all samples does not near its asymptote (Fig. 4), indicating that only a portion of the species were collected. The total species richness at the sampling site, estimated using the sample-based Chao-1 estimator, is 243 species (95\% CI 196-333; Fig. 5; Table 1). The results were similar using the ACE estimator (240 species) and the ICE estimator (257 species). The total species richness of the tachinid community in the area, estimated using the sample-based Chao-1 estimator, for the period from June 2017 to October 2017 was 161 species (95\% CI 111-278; Fig. 5, Table 1), and from 6 July 2018 to 6 July 2019 was estimated to be 152 species (95\% CI 120-220; Fig. 5, Table 1).

Temporal distribution. Data analyses were based on all specimens captured between 2017 and 2019 (Supplementary Information File 1). Summer is the most species-rich season, with 257 species captured in the summer of 2017 (Table 2). Spring, conversely, is the season with the most specimens, with 257 specimens collected in the spring of 2019 (Table 2). Two Exoristinae species comprised almost $50 \%$ of all specimens collected in the spring of 2019; other dominant species were Phorocera normalis (31.1\%) and Phryno vetula (16\%).

The NMDS ordination for tachinid communities was plotted in Fig. 6. A clear division of the tachinid fauna were observed during the three seasons (Fig. 6). The stress obtained for this dimensionality was 0.1325 , and the MRPP of the seasonal patterns observed in the NMDS plot was statistically significant $(\mathrm{P}=0.001, \mathrm{~A}=0.08723)$, 
(a) The proportion of subfamilies by species number

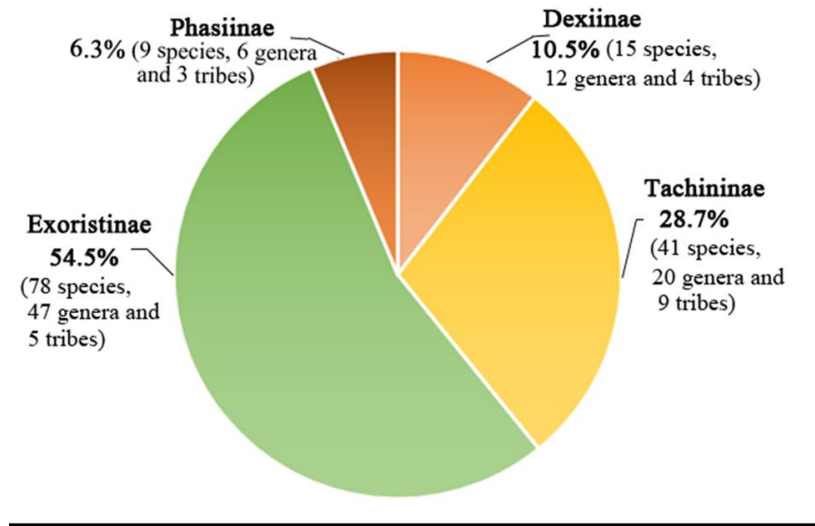

(b) The proportion of subfamilies by specimen number

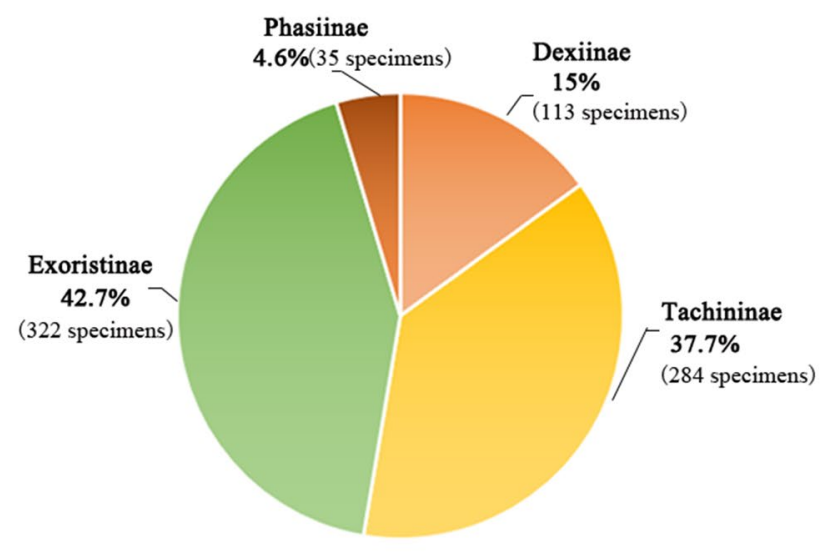

Figure 2. Pie chart of the proportion of each tachinid subfamily by (a) the number of species and (b) by the number of specimens.

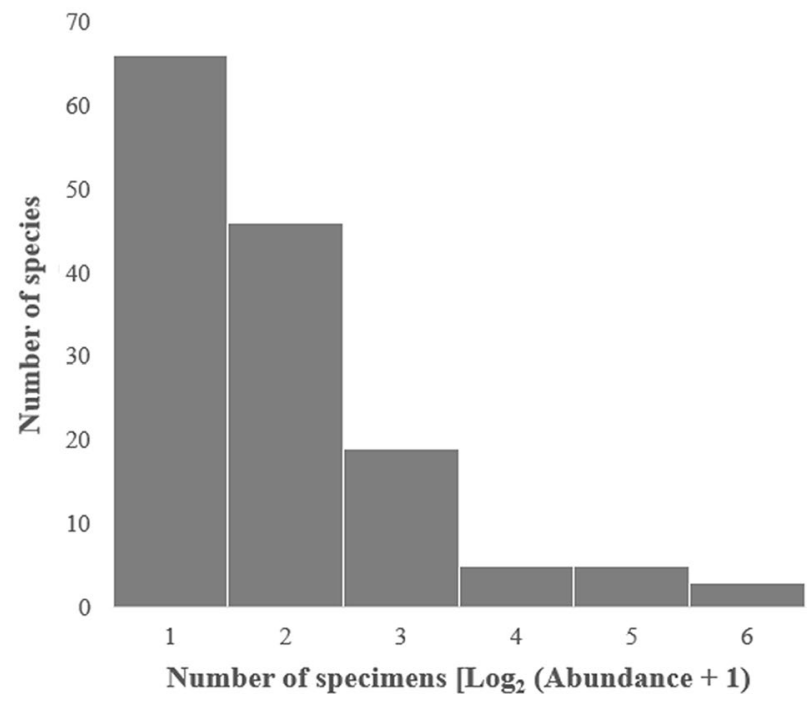

Figure 3. Rank-abundance of tachinid species sampled in this study. The $\mathrm{x}$-axis is the log base two of the specimens abundance plus 1. 


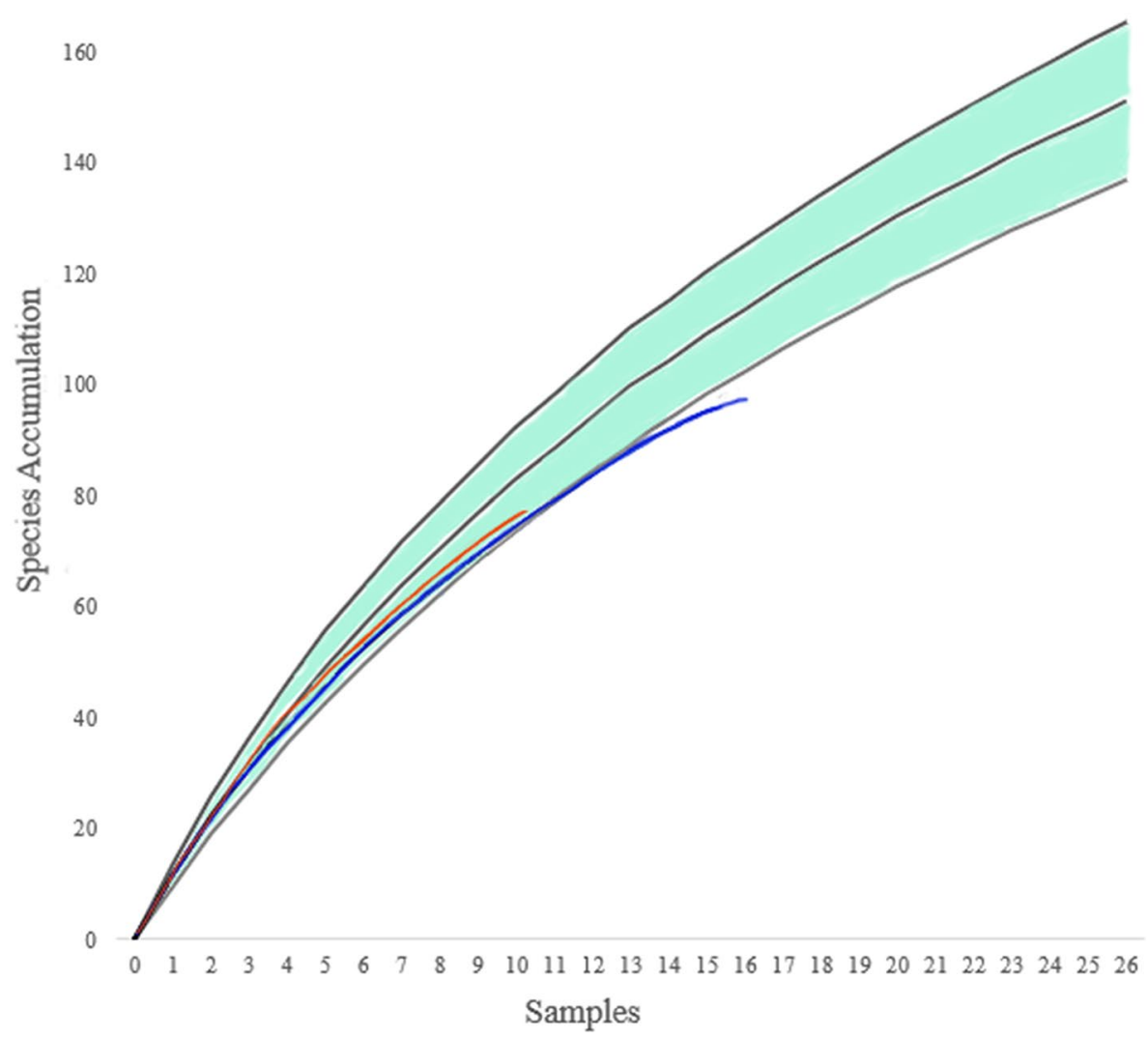

Figure 4. Accumulation curves of tachinid species against the number of samples. The green highlight is the species richness for 2017-2019 with the species richness accumulation in the center $\pm 95 \%$ CI. The red curve and the blue curve are the species richness accumulation curves for 2017 and 2018-2019, respectively. Curves are based on 1,000 randomizations.

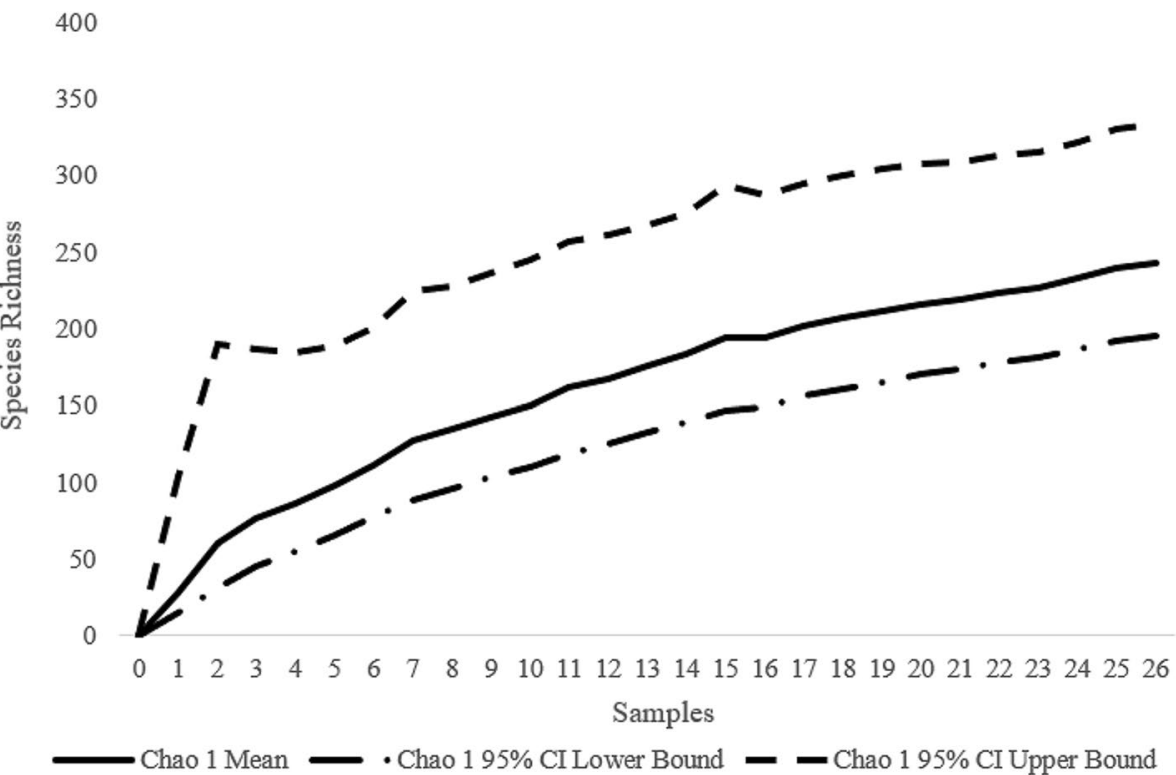

Figure 5. Estimated total species richness (Chao-1 estimator) with $95 \%$ confidence intervals for trap. 


\begin{tabular}{|l|l|l|l|l|}
\hline Year & $\mathbf{2 0 1 7}$ & $\mathbf{2 0 1 8}$ & $\mathbf{2 0 1 9}$ \\
\hline Season & Summer & Fall & Fall & Spring \\
\hline No. of species & 62 & 21 & 38 & 27 \\
\hline No. of specimens & 191 & 61 & 126 & 257 \\
\hline
\end{tabular}

Table 2. The number of tachinid species and specimens over summer 2017 to spring 2019. The data for the summer of 2018 and 2019 is insufficient, so there is no analysis carried out.

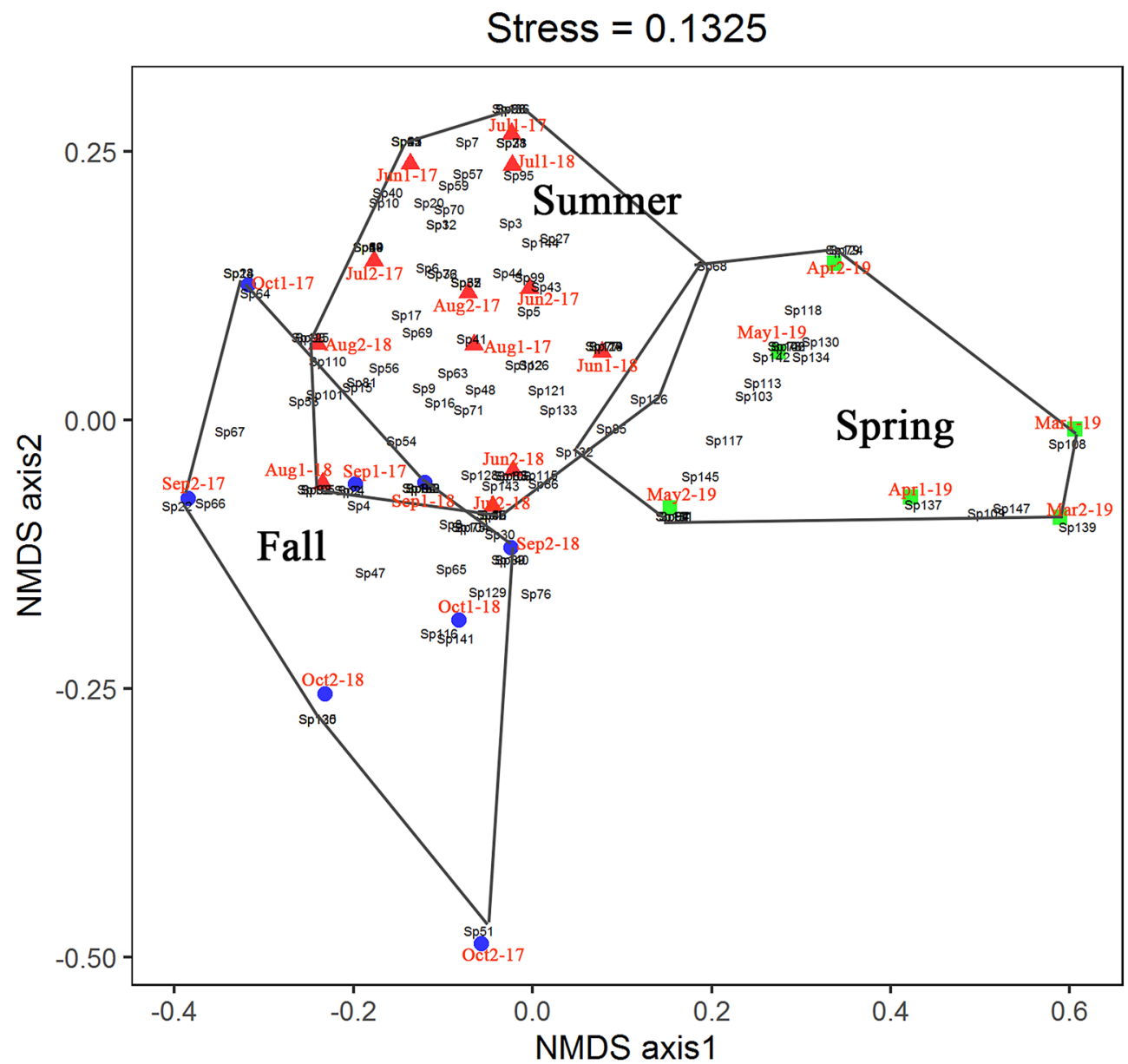

Figure 6. The 2-dimensional NMDS ordination configuration plot showing sample dates and points (black) for species using the Bray-Curtis dissimilarity matrix. Polygons group spring, summer and fall seasons.

indicating that the composition of the tachinid community varies significantly over seasons. Only 13 species were shared between spring and summer, eight species between spring and fall, 22 species between summer and fall, and only four species were shared among all three seasons.

The indicator species analysis was adopted to reveal the seasonal variation of dominant tachinid species. Three species dominated in spring: Phorocera normalis $(\mathrm{IV}=100, \mathrm{MCT}, \mathrm{P}=0.001)$, Triarthria sp.1 $(\mathrm{IV}=65.3$, MCT, $\mathrm{P}=0.001)$ and Panzeria mira (IV $=64.9, \mathrm{MCT}, \mathrm{P}=0.001$ ). Siphona (Siphona) sp. 2 is the unique dominant species in summer $(\mathrm{IV}=52.2, \mathrm{MCT}, \mathrm{P}=0.024)$ and Prosena siberita is the unique dominant species in fall $(\mathrm{IV}=56.3$, MCT, $\mathrm{P}=0.008$ ).

Based on the long-term research, we assessed voltinism and phenological patterns of several species of the tachinid community. Admontia blanda, Admontia continuans, Carcelia bombylans, Ectophasia rotundiventris, Peribaea glabra and Siphona paludosa have more than two generations per year (Supplementary Information File 1). Ectophasia crassipennis, Leiophora innoxia, Pales carbonata and Pales pavida may have two generations per year (Supplementary Information File 1). The species Admontia gracilipes, Dinera xuei, Estheria magna, Hamaxiella brunnescens, Linnaemya picta, Panzeria mira, Pexopsis pollinis, Phebellia carceliaeformis, Phorocera normalis, Phryno vetula, Phytomyptera zonella, Prosena siberita, Tachina ursina, and Uromedina atrata are likely to be univoltine (Supplementary Information File 1). In addition, we found that many species only appear in 


\begin{tabular}{|c|c|c|c|c|c|c|c|c|}
\hline \multirow[b]{2}{*}{ Locality } & \multirow[b]{2}{*}{ Latitude } & \multirow[b]{2}{*}{ Elevation } & \multicolumn{3}{|c|}{$\begin{array}{l}\text { Estimated species } \\
\text { richness (Chao } 1 \text { or Chao } \\
295 \% \text { CI) }\end{array}$} & \multicolumn{2}{|c|}{ Diversity metrics } & \multirow[b]{2}{*}{ References } \\
\hline & & & Mean & Lower & Upper & $\mathrm{eH}^{*}$ & Simpson* & \\
\hline Central Italy (understorey) & $45^{\circ}$ & 26 & 52 & - & 150 & - & - & Stireman et al. ${ }^{67}$ \\
\hline Ohio & $39^{\circ}$ & 250 & 205 & 192 & 217 & - & - & Inclán \& Stireman ${ }^{32}$ \\
\hline Beijing & $39^{\circ}$ & 1200 & 243 & 196 & 333 & 54.68 & 26.6 & This study \\
\hline Arizona & $32^{\circ}$ & 1575 & 122.7 & 97 & 189 & - & - & Stireman $^{34}$ \\
\hline Maryland & $39^{\circ}$ & 111.89 & 172.5 & 129.4 & 266.7 & 33.2 & 18.3 & Burington et al. ${ }^{68}$ \\
\hline Ohio-1 & $39^{\circ}$ & 251 & 152.8 & 133.6 & 194.2 & 44.1 & 21 & \\
\hline Ohio-2 & $39^{\circ}$ & 269 & 116.6 & 92.9 & 173.2 & 23.7 & 9.9 & \\
\hline Arizona & $32^{\circ}$ & 1575 & 135.0 & 102.0 & 215.4 & 32.3 & 18.2 & \\
\hline Costa Rica & $10^{\circ}$ & 1600 & 440.1 & 386.6 & 523.3 & 133.7 & 57.1 & \\
\hline Ecuador-1 & $0^{\circ}$ & 2100 & 398.0 & 355.0 & 468.3 & 60.9 & 22.1 & \\
\hline Ecuador-2 & $0^{\circ}$ & 2173 & 240.0 & 193.0 & 327.2 & 95.6 & 68.2 & \\
\hline Ecuador-3 & $-4^{\circ}$ & 3000 & 103.9 & 86.7 & 146.0 & 49.8 & 33.4 & \\
\hline
\end{tabular}

Table 3. Summary information of tachinid species richness estimates from different zoogeographical regions.

certain seasons. For example, Phorocera normalis, Pexopsis pollinis, Tachina ursina, Gonia ussuriensis were collected only in spring (Supplementary Information File 1). Dinera xuei, Leiophora innoxia, Uromedina atrata, Linnaemya picta were collected only in summer (Supplementary Information File 1). Bithia modesta, Phytomyptera zonella, Peribaea tibialis were collected only in fall (Supplementary Information File 1). Several of the potential bivoltine species were also seasonally restricted: Pales pavida exhibited split distributions over spring and fall, Prosena siberita, Admontia blanda, Admontia continuans, Leiophora innoxia, Ectophasia crassipennis, Ectophasia rotundiventris, Siphona (Siphona) paludosa were absent in spring, Phryno vetula and Panzeria mira were absent from the fall samples (Supplementary Information File 1). Phorocera normalis was the earliest species of the year that appeared, followed by Tachina ursina which appeared from 15 to 22 March 2019. Ectophasia rotundiventris, Pales pavida, Graphogaster buccata, Phytomyptera zonella, and Suensonomyia nudinerva were found in late fall (Supplementary Information File 1).

\section{Discussion}

This study demonstrates the species richness and temporal distribution of Tachinidae sampled using a Malaise trap in Baihua Mountain Reserve over a sampling period of 73 weeks. A total of 755 tachinid individuals were collected and sorted into 144 species in 85 genera, including several species and genera newly recorded in China and one new species (Supplementary Information File 1 and Supplementary Information File 2). Our results indicate the effectiveness of Malaise traps in comprehensive insect community monitoring, and demonstrated that the Chinese tachinid fauna needs further study as more species are likely to be discovered.

The high species richness found in our study suggests that the species richness of tachinids in Beijing and northern China might be vastly underestimated. Initially, the number of species captured in this study is surprisingly high in comparison to the current local species records. The captured species number accounts for $55.8 \%$ and $81.7 \%$ of the published tachinid species and genera number in Beijing, $26.5 \%$ and $49.7 \%$ in northern China, and $11.5 \%$ and $30.4 \%$ of the tachinid species and genera number in China ${ }^{59}$. Such high percentages resulted from our sampling in a generally well-collected region, suggesting a largely undiscovered diversity of the tachinid species in this area. Another line of evidence is that the Chao-1 estimator indicated that the total tachinid species richness (Fig. 5, Table 1) in this single site is close to the current number of tachinid species recorded from across Beijing ${ }^{59}$. In fact, up to $77.8 \%$ of the species in our collection are represented by only one or two specimens (Fig. 3). The heavily skewed species abundance distribution curves (Figs. 3 and 4) suggest that many species in the community have not yet been sampled, and that the number of tachinid species will grow as the collecting time increases (Fig. 4).

The high number of species of Tachinidae in our study site might be correlated with the wide variety of climates and habitats located in Baihua Mountain Reserve ${ }^{11,60}$. This reserve contains various microclimates and microhabitats, including coniferous forest, open woodland, broad-leafed forest, grassland, and streams, with elevations ranging from 500 to $2043 \mathrm{~m}^{61}$. Our sampling site was located at the forest and farmland edge, with an abundance of wild open grassland that is important in maintaining a high level of insect biodiversity ${ }^{62}$. Although this edge habitat could encourage greater species richness and exotic species as it attracts insects from both open and forest-associated communities ${ }^{63-66}$, this location only represents two of the common habitats of this reserve. Therefore, the estimated 243 species from one single trapping site are very likely to be a subset of species occurring in the Baihua Mountain Reserve. The hyper-diversity of tachinid communities reinforces the needs for expanding monitoring efforts to uncover the diversity of not only tachinids, but also many other taxa in the region.

This study demonstrated the high sampling efficiency of Malaise traps. We recorded a relatively higher number of species in comparison to previous studies conducted in locations of similar latitudes over similar sampling periods $^{32,34,67,68}$ (Table 3). For example, Stireman ${ }^{34}$ documented 79 species, and estimated a total of 122 species. 
Inclán and Stireman ${ }^{32}$ recorded a community of 117 species and estimated the total species to be 190 . Despite the differences in the habitats (natural versus disrupted) between the previous studies ${ }^{32,34}$ and the current study, one explanation for this discrepancy may be the different sampling methods (pan traps versus Malaise traps). The pan trap is designed to catch insects which rely on visual orientation and active near the ground, while Malaise traps passively intercept insects flying at various heights ${ }^{69-71}$. Thus, the sampling efficiency of Malaise taps are higher than pan traps for Tachinidae biodiversity surveys.

The diversity and population dynamics of tachinids can reflect the hosts and their hostplants due to their trophic level as parasitoids of herbivorous insects ${ }^{30}$. Based on the most comprehensive study to date ${ }^{52}$, we found host information for only 50 of the 144 species recorded in this study (Supplementary Information File 4), comprising 810 host species belonging to six orders, 59 families and 450 genera (Supplementary Information File 4). Surprisingly, of the 50 species with known hosts, only 28 species had their host species also recorded in Baihua Mountain Reserve, suggesting the lack of host species studies of this remarkably diverse group of insects in Beijing and in north China. Understanding the relationship between these parasitoids and their hosts can be used as a baseline for the management of reserves, and as indicators of the diversity and population dynamics of their hosts ${ }^{30}$.

\section{Data availability}

All data generated or analysed during this study are included in this published article (and its Supplementary Information files).

Received: 14 April 2021; Accepted: 1 November 2021

Published online: 12 November 2021

\section{References}

1. Wilson, E. O. The little things that run the world (The importance and conservation of invertebrates). Conserv. Biol. 1, 344-346 (1987).

2. Stork, N. E. How many species are there?. Biodivers. Conserv. 2, 215-232 (1993).

3. Erwin, T. L. Tropical forests: Their richness in Coleoptera and other arthropod species. Coleopts. Bull. 36, 74-75 (1982).

4. Novotny, V. et al. Low host specificity of herbivorous insects in a tropical forest. Nature 416, 841-844 (2002).

5. Stork, N. E. How many species of insects and other terrestrial arthropods are there on earth?. Annu. Rev. Entomol. 63, 31-45 (2018).

6. Linnaeus, C. Amoenitates Academicae, seu Dissertationes Variae Physicae, Medicae, Botanicae, Volume 2. (Laurentium Salvium, 1749).

7. Linnaeus, C. Systema Naturae per Regna tria Naturae, Secundum Classes, Ordines, Genera, Species cum Characteribus, Differentiis, Synonymis, Locis. (Laurentium Salvium, 1758).

8. Metcalf, Z. P. How many insects are there in the world?. Entomol. News 51, 219-222 (1940).

9. Ødegaard, F. The relative importance of trees versus lianas as hosts for phytophagous beetles (Coleoptera) in tropical forests. J. Biogeogr. 27, 283-296 (2000).

10. Geiger, M. F. et al. The global Malaise trap program-how well does the current barcode reference library identify flying insects in Germany? Biodivers. Data J. 4, e10671 (2016).

11. D'Souza, M. L. \& Hebert, P. D. N. Stable baselines of temporal turnover underlie high beta diversity in tropical arthropod communities. Mol. Ecol. 27, 2447-2460 (2018).

12. Srivathsan, A. et al. Rapid, large-scale species discovery in hyperdiverse taxa using 1D MinION sequencing. Bmc. Biol. 17, 96 (2019).

13. Wu, Y. et al. Explaining the species richness of birds along a subtropical elevational gradient in the Hengduan Mountains. J. Biogeogr. 40, 2310-2323 (2013).

14. Morelli, F. et al. Taxonomic diversity, functional diversity and evolutionary uniqueness in bird communities of Beijing's urban parks: Effects of land use and vegetation structure. Urban For. Urban Green. 23, 84-92 (2017).

15. White, E. P. Spatiotemporal scaling of species richness: Patterns, processes and implications. In Scaling biodiversity (eds Storch, D. et al.) 325-346 (Cambridge University Press, 2007).

16. Schwartz, M. D. Phenology: An Integrative Environmental Science. (Springer, 2013).

17. Brehm, G., Colwell, R. K. \& Kluge, J. The role of environment and mid-domain effect on moth species richness along a tropical elevational gradient. Glob. Ecol. Biogeogr. 16, 205-219 (2007).

18. Sundqvist, M. K., Sanders, N. J. \& Wardle, D. A. Community and ecosystem responses to elevational gradients: Processes, mechanisms, and insights for global change. Annu. Rev. Ecol. Evol. Syst. 44, 261-280 (2013).

19. Le, C. M., Wilson, S. W. \& Soulier-Perkins, A. Elevational gradient of Hemiptera (Heteroptera, Auchenorrhyncha) on a tropical mountain in Papua New Guinea. PeerJ 3, e978 (2015).

20. McCravy, K. W. A review of sampling and monitoring methods for beneficial arthropods in agroecosystems. Insects 9, 170 (2018).

21. Karlsson, D. et al. The Swedish Malaise trap project: A 15 year retrospective on a countrywide insect inventory. Biodivers. Data J. 8, e47255 (2020).

22. Borkent, A. et al. Remarkable fly (Diptera) diversity in a patch of Costa Rican cloud forest: Why inventory is a vital science. Zootaxa 4402, 53-90 (2018).

23. Fraser, S. E. M., Dytham, C. \& Mayhew, P. J. The effectiveness and optimal use of Malaise traps for monitoring parasitoid wasps. Insect Conserv. Divers. 1, 22-31 (2008).

24. Gaston, K. J., Gauld, I. D. \& Hanson, P. The size and composition of the hymenopteran fauna of Costa Rica. J. Biogeogr. 23, 105-113 (1996).

25. Townes, H. K. Design of a Malaise trap. Proc. Entomol. Soc. Wash. 64, 253-262 (1962).

26. O'Hara, J. E. History of tachinid classification (Diptera, Tachinidae). ZooKeys 316, 1-34 (2013).

27. O'Hara, J. E., Henderson, S. J. \& Wood, D. M. Preliminary Checklist of the Tachinidae of the World. Version 2.1. http://www.nadsd iptera.org/Tach/WorldTachs/Checklist/Worldchecklist.html (2020).

28. Stireman, J. O., O’Hara, J. E. \& Wood, D. M. Tachinidae: Evolution, behavior, and ecology. Annu. Rev. Entomol. 51, 525-555 (2006).

29. Cerretti, P. et al. Signal through the noise? Phylogeny of the Tachinidae (Diptera) as inferred from morphological evidence. Syst. Entomol. 39, 335-353 (2014).

30. Stireman, J. O., Dyer, L. A. \& Greeney, H. F. Specialised generalists? Food web structure of a tropical tachinid-caterpillar community. Insect Conserv. Diver. 10, 367-384 (2017).

31. Belshaw, R. Tachinid (Diptera) assemblages in habitats of a secondary succession in southern Britain. Entomology 111, 151-161 (1992). 
32. Inclán, D. J. \& Stireman, J. O. Tachinid (Diptera: Tachinidae) Parasitoid diversity and temporal abundance at a single site in the northeastern United States. Ann. Entomol. Soc. Am. 104, 287-296 (2011).

33. Cerretti, P., Whitmore, D., Mason, F. \& Taglianti, A. V. Survey on the spatio-temporal distribution of tachinid flies: Using Malaise traps (Diptera, Tachinidae). In Invertebrati diuna foresta della Pianura Padana, Bosco della Fontana, Secondo contributo (eds Cerretti, P. et al.) 229-256 (Springer, 2004).

34. Stireman, J. O. Alpha and beta diversity of a tachinid parasitoid community. Ann. Entomol. Soc. Am. 101, 362-370 (2008).

35. Pei, W. Y. et al. Species diversity of Tachinidae in Baihuashan National Nature Reserve of Beijing, China. J. Environ. Entomol. 41, 1218-1225 (2019).

36. Zhao, Y. et al. Fauna resource investigation of Tachinidae (Diptera) from Mt. Huangyi, Eastern Liaoning, China. J. Environ. Entomol. 41, 1208-1217 (2019).

37. Zhang, Y. Z. et al. Fauna resource investigation of Tachinidae (Diptera) from the grasslands, Inner Mongolia of China. J. Environ. Entomol. 40, 1353-1363 (2018).

38. Zhang, C. T. et al. Preliminary investigation on Tachinidae (Diptera) of Hanma National Nature Reserve, Inner Mongolia, China. J. Environ. Entomol. 35, 257-264 (2017).

39. Liang, H. C. et al. Fauna resource of Tachinidae in Liaoning Hun River Source Nature Reserve of China. J. Environ. Entomol. 38, 1214-1223 (2016).

40. Zhang, C. T. et al. Faunistic investigation of Tachinidae in Liaoning Bailang Mountain National Nature Reserve of China. J. Environ. Entomol. 37, 726-734 (2015).

41. Zhang, D. et al. Study on Tachinidae fauna in Songshan National Nature Reserve of Beijing, China. Chin. J. Vector Biol. Control 22, 459-465 (2011).

42. Herting, B. \& Dely-Draskovits, A. Family Tachinidae. In Catalogue of Palaearctic Diptera. Volume 13. Anthomyiidae-Tachinidae. (eds Soós, A. \& Papp, L.) 118-458 (Hungarian Natural History Museum, 1993).

43. O'Hara, J. E. \& Henderson, S. J. World Genera of the Tachinidae (Diptera) and Their Regional Occurrence. Version 11.0. http://www. nadsdiptera.org/Tach/WorldTachs/Genera/Worldgenera.html (2020).

44. Tschorsnig, H. P. \& Richter, V. A. Family Tachinidae. In Contributions to a Manual of Palaearctic Diptera (with special reference to flies of economic importance) (eds Papp, L. \& Darvas, B) 691-827 (Higher Brachycera Science Herald Press, 1998).

45. Cerretti, P., Tschorsnig, H. P., Lopresti, M. \& Giovanni, F. D. MOSCHweb: A matrix-based interactive key to the genera of the Palaearctic Tachinidae (Insecta, Diptera). ZooKeys 205, 5-18 (2012).

46. Andersen, S. Revision of European species of Phytomyptera Rondani (Diptera: Tachinidae). Insect Syst. Evol. 19, 43-80 (1988).

47. Andersen, S. The Siphonini (Diptera: Tachinidae) of Europe. Fauna Entomol. Scand. 33, 1-146 (1996).

48. Chao, C. M. et al. Tachinidae. In Flies of China Vol. 2 (eds Xue, W. Q. \& Chao, C. M.) (Liaoning Science and Technology Press, 1998).

49. Chao, C. M. et al. Fauna Sinica. Insecta. Vol. 23. Diptera. Tachinidae (1) (Science Press, 2001).

50. O'Hara, J. E., Shima, H. \& Zhang, C. T. Annotated catalogue of the Tachinidae (Insecta: Diptera) of China. Zootaxa 2190, 1-236 (2009).

51. Tachi, T. \& Shima, H. Systematic study of the genus Peribaea Robineau-Desvoidy of East Asia (Diptera: Tachinidae). Tijdschr. voor Entomol. 145, 115-144 (2002).

52. Tschorsnig, H. P. Preliminary Host Catalogue of Palaearctic Tachinidae (Diptera). http://www.nadsdiptera.org/Tach/WorldTachs/ CatPalHosts/Home.html (2017).

53. Zhang, C. T., Shima, H. \& Chen, X. L. A review of the genus Dexia Meigen in the Palearctic and Oriental Regions (Diptera: Tachinidae). Zootaxa 2705, 1-81 (2010).

54. Colwell, R. K. Estimates: Statistical Estimation of Species Richness and Shared Species from Samples. Version 9.1.0. http://viceroy. eeb.uconn.edu/estimates/ (2019).

55. Oksanen, J. F. et al. Vegan: Community Ecology Package. R Package Version 2.4-3. https://CRAN.R-project.org/package=vegan. Accessed 20 May 2018 (2017).

56. Mielke, P. W. 34 Meteorological applications of permutation techniques based on distance functions. Handb. Stat. 4, 813-830 (1984).

57. Ge, Y. et al. Exotic spartina alterniflora invasion changes temporal dynamics and composition of spider community in a salt marsh of Yangtze Estuary, China. Estuar. Coast. Shelf. Sci. 239, 106755 (2020).

58. Haq, F. et al. Multivariate approach to the classification and ordination of the forest ecosystem of Nandiar valley western Himalayas. Ecol. Indic. 80, 232-241 (2017).

59. Oara, J. E., Zhang, C. T. \& Shima, H. Catalogue of the Tachinidae (Insecta: Diptera) of China. In Catalogue of Life China: 2021 Annual Checklist, Volume 2 Animals, Insect (VI), Diptera (3) (eds Yang, D. et al.) 845-1170 (The Biodiversity Committee of Chinese Academy of Sciences, 2021).

60. McCain, C. M. \& Grytnes, J. A. Elevational gradients in species richness. In Encyclopedia of Life Sciences (eds Wiley, J. \& Ltd, S.) 1-10 (Wiley, 2010).

61. Zhang, J. T., Xu, B. \& Li, M. Vegetation patterns and species diversity along elevational and disturbance gradients in the Baihua Mountain Reserve, Beijing, China. Mt. Res. Dev. 33, 170-178 (2013).

62. Huang, Y. et al. The effects of habitat area, vegetation structure and insect richness on breeding bird populations in Beijing urban parks. Urban For. Urban Green. 14, 1027-1039 (2015).

63. Eldegard, K., Totland, Ø. \& Moe, S. R. Edge effects on plant communities along power line clearings. J. Appl. Ecol. 52, 871-880 (2015).

64. Fahrig, L. Effects of habitat fragmentation on biodiversity. Annu. Rev. Ecol. Evol. Syst. 34, 487-515 (2003).

65. Harper, K. A. et al. Edge influence on forest structure and composition in fragmented landscapes. Conserv. Biol. 19, 768-782 (2005).

66. Laurance, W. F. et al. Habitat fragmentation, variable edge effects, and the landscape-divergence hypothesis. PLoS ONE 2, e1017 (2007).

67. Stireman, J. O. III., Cerretti, P., Whitmore, D., Hardersen, S. \& Gianelle, D. Composition and stratification of a tachinid (Diptera: Tachinidae) parasitoid community in a European temperate plain forest. Insect Conserv. Divers. 5, 346-357 (2012).

68. Burington, Z. L. et al. Latitudinal patterns in tachinid parasitoid diversity (Diptera: Tachinidae): A review of the evidence. Insect Conserv. Divers. 13, 419-431 (2020).

69. Campbell, J. W., Hanula, J. L. \& Waldrop, T. A. Effects of prescribed fire and fire surrogates on floral visiting insects of the blue ridge province in North Carolina. Biol. Conserv. 134, 393-404 (2007).

70. Alfred, D. J. et al. A study on five sampling methods of parasitic hymenopterans in rice ecosystem. Biol. Control. 32, 187-192 (2018).

71. Wells, W. \& Decker, T. A comparison of three types of insect traps for collecting non-Formicidae Hymenoptera on the Island of Dominica. Southwest. Entomol. 31, 59-68 (2006).

\section{Acknowledgements}

We are grateful to Yufan Chen and Ziyue Wan (Beijing Forestry University) for their assistance during the fieldwork and for helping with specimens sorting in the laboratory. We thank Kathryn McNamara for English 
language editing. This study was supported by the Beijing Forestry University Outstanding Young Talent Cultivation Project (No. 2019JQ03018) and National Natural Science Foundation of China (Nos. 31872964, 31572305 and 31970443).

\section{Author contributions}

D.Z., W.Y.P. and L.P.Y. conceived and designed the study. W.Y.P. analyzed the data and wrote the manuscript. W.Y.P., D.Z., L.P.Y. and Q.K.W. made contributions to the discussion. N.Y. and F.X.D. performed the samples collection. C.T.Z. identified all of tachinid specimens. W.Y.P., L.P.Y., D.Z., T.P. and Q.K.W. revised the manuscript, and all authors approved the final version.

\section{Competing interests}

The authors declare no competing interests.

\section{Additional information}

Supplementary Information The online version contains supplementary material available at https://doi.org/ 10.1038/s41598-021-01659-8.

Correspondence and requests for materials should be addressed to D.Z.

Reprints and permissions information is available at www.nature.com/reprints.

Publisher's note Springer Nature remains neutral with regard to jurisdictional claims in published maps and institutional affiliations.

(c) (i) Open Access This article is licensed under a Creative Commons Attribution 4.0 International License, which permits use, sharing, adaptation, distribution and reproduction in any medium or format, as long as you give appropriate credit to the original author(s) and the source, provide a link to the Creative Commons licence, and indicate if changes were made. The images or other third party material in this article are included in the article's Creative Commons licence, unless indicated otherwise in a credit line to the material. If material is not included in the article's Creative Commons licence and your intended use is not permitted by statutory regulation or exceeds the permitted use, you will need to obtain permission directly from the copyright holder. To view a copy of this licence, visit http://creativecommons.org/licenses/by/4.0/.

(C) The Author(s) 2021 